\title{
Nosocomial urinary tract infections caused by extended-spectrum beta-lactamase uropathogens: Prevalence, pathogens, risk factors, and strategies for infection control
}

\author{
Khaireddine Bouassida, MD; Mehdi Jaidane, MD; Olfa Bouallegue, MD; Ghassen Tlili, MD;' Habiba Naija, \\ $M D^{2}$ Ali Tahar Mosbah, $M D^{1}$
}

'Department of Urology, Hospital of Sahloul, Sousse, Tunisia; ${ }^{2}$ Department of Microbiology, Hospital of Sahloul, Sousse, Tunisia

Cite as: Can Urol Assoc J 2016;10(3-4):E87-93. hittp://dx.doi.org/10.5489/cuai.3223

\section{Abstract}

Introduction: Our goal was to investigate the prevalence and antibiogram pattern of extended spectrum beta-lactamase (ESBL) production among uropathogens using isolates from urine samples collected at the Department of Urology in the Sahloul Hospital, Tunisia We also aimed to identify the risk factors for nosocomial urinary tract infections (UTIs) in patients who underwent transurethral resection of the prostate (TURP) and the measures for infection control.

Methods: Laboratory records of a five-year period from January 2004 to December 2008 were submitted for retrospective analysis to determine the incidence of ESBL infections. A total of 276 isolates were collected. A case-control study involving comparisons between two groups of patients who underwent TURP was performed to determine the risk factors for ESBL infection. Group 1, designated case subjects, included 51 patients with nosocomial UTI after TURP. Group 2, designated control subjects, consisted of 58 randomly selected patients who underwent TURP without nosocomial UTI in the same period. Factors suspected to be implicated in the emergence of ESBL infection were compared between the two groups in order to identify risk factors for infection. A univariate regression analysis was performed, followed by a multivariate one. Results: The annual prevalence of ESBL infection ranged from $1.3-2.5 \%$. After performing univariate and multivariate regression analysis, the main risk factors for ESBL infections were identified as: use of antibiotics the year preceding the admission, duration of catheter use, and bladder washout $(p=0.012, p=0.019$, and $\mathrm{p}<0.001$.

Conclusions: Urologists have to perform a good hemostasis, especially in endoscopic resections, in order to avoid bladder irrigation and bladder washout and to reduce the time of bladder catheterization, which is a strong risk factor of nosocomial UTIs.

\section{Introduction}

Hospital infections have become a growing healthcare challenge in recent decades and serious concerns have been expressed over the rise in antimicrobial resistance among pathogens causing hospital-acquired infections. ${ }^{1}$ Nosocomially acquired urinary tract infection (NAUTI) is one of the most common hospital-acquired infections..$^{2,3}$ This infection is not already present or incubating at the time of admission, but is acquired during hospital stay. Its definition requires a 48-hour delay after admission before symptoms appear. ${ }^{1,4,5} \mathrm{NAUTI}$ has become one of the most important quality parameters for urological surgery. The problem is further exacerbated by the emergence of drug resistance among uropathogens in the form of extended spectrum beta-lactamase (ESBL) production. In fact, the first outbreak of ESBL-producing organisms was reported in 1983 in Germany ${ }^{1}$ and involved chromosomal- or plasmid-mediated beta-lactamases (enzymes that cleave the beta-lactam ring) that had mutated from pre-existing broad-spectrum beta-lactamases as a consequence of the extensive use of third- generation cephalosporins and aztreonam. ${ }^{6}$ Those ESBL-producing pathogens are now globally recognized as major causes of nosocomial acquired infections. ${ }^{7,8}$

The control of antimicrobial resistance has become a major global healthcare concern. ${ }^{9}$ The present study was undertaken to investigate the prevalence and antibiogram pattern of ESBL production among Gram-negative uropathogens using isolates from urine samples collected at the Department of Urology in Sahloul Hospital, Tunisia. It also aimed at identifying the risk factors for this type of infections in patients who underwent transurethral resection of the prostate (TRUP) and the possible measures for infection control. 


\section{Methods}

\section{Data processing}

A retrospective analysis was performed in the Department of Urology of Sahloul Hospital over a five-year period from January 2004 to December 2008. A total of 276 ESBLproducing isolates were collected from urine samples of patients. Patients already having UTI at the time of admission were excluded from our study.

A case-control study involving comparisons between two groups of patients who underwent TURP was performed to determine the risk factors for ESBL emergence. Group 1, designated case subjects, included 51 patients with NAUTI caused by ESBL-producing uropathogens after TURP. Group 2 , designated control subjects, consisted of 58 randomly selected patients who underwent TURP without UTI in the same period. Factors suspected to be implicated in the emergence of ESBL infection were compared between the two groups in order to identify risk factors for ESBL infection. A univariate regression analysis was performed, followed by a multivariate one.

\section{Urine culture and bacterial identification}

Urine culture was performed quantitatively and uropathogens were identified according to routine laboratory methods, including the ID-Biotes $\mathrm{t}^{\circledR}$ system (Biotest, Dreieich, Germany).

Antimicrobial susceptibility testing was performed using the disk diffusion method and interpreted according to the recommendations of the Commite de l'Antibiogramme de la Société Francaise de Microbiologie (CA-SFM).

\section{ESBL detection}

The antibiotic susceptibility patterns of the ESBL-producing organisms were identified using the double disc synergy test. NAUTI was defined according to criteria of the Centre for Disease Control (CDC, Atlanta, U.S.) (Table 1).

\begin{tabular}{|c|c|}
\hline Type of infection & Definition \\
\hline $\begin{array}{l}\text { Symptomatic } \\
\text { infection }\end{array}$ & $\begin{array}{l}\text { A positive urine culture of } \geq 105 \text { colony-forming } \\
\text { units/ml, with no more than two species of } \\
\text { uropathogen microorganisms associated with } \\
\text { clinical signs of infection, such as fever, cystitis, } \\
\text { suprapubic or loin pain, epididymoorchitis. }\end{array}$ \\
\hline $\begin{array}{l}\text { Asymptomatic } \\
\text { infection }\end{array}$ & $\begin{array}{c}\text { A positive urine culture of } \geq 104 \mathrm{CFU} / \mathrm{ml} \\
\text { with no more two species of uropathogen } \\
\text { microorganisms associated with no signs or } \\
\text { symptoms. }\end{array}$ \\
\hline
\end{tabular}

\section{Statistical analysis}

The differences and similarities between categorical groups were compared using the chi-squared test or Fisher's exact test, when appropriate. Continuous variables were compared using the student t-test. Univariate and then multivariate regression analysis were used to examine the association of various risk factors of NAUTI caused by ESBL uropathogens in patients who underwent TURP. Multiple logistic regression using a stepwise method was performed, including only variables with $p \leq 0.05$ in univariate regression. All analyses were conducted using SPSS version 19.0, with significance set at the $5 \%$ level. The odds ratio (OR) was calculated with a confidence interval $(\mathrm{Cl})$ of $95 \%$.

\section{Results}

\section{Descriptive epidemiology}

The results revealed that a total number of 276 cases of ESBL urinary infections were reported between January 2004 and December 2008. The annual incidence ranged from 42-68 new cases; the annual prevalence ranged from 1.3-2.5\% (average of $1.9 \%$ ) of all patients hospitalized in the urology department. The mean age of patients was 62 years (range: 4-98 years), with more than a half aged between 60 and 80 years. The gender ratio was 3:2 men to women. About half the patients, $139 / 276(50.4 \%)$, had underlying chronic diseases, with 63/276 (22.8\%) having hypertension. Past history of UTI in the last year was found in 12/276 (4.3\%) of the cases. The use of antibiotics in the preceding year was noted in $64 / 276(23.2 \%)$ of the cases. TURP alone was performed in 51/276 (18.5\%) of the patients and associated with resection of bladder tumour in nine cases (Table 2).

\section{Risk factors for ESBL infections}

The univariate analysis shows that the difference between the mean age of the case group vs. the control group was not statistically significant ( 71 vs. 72 years, respectively, $p=0.829$ ). Past history of diabetes, hypertension, and heart disease were not predictors of ESBL infections in our study. However, the difference was statistically significant between the two groups concerning urologic past history, use of antibiotics, past history of UTI, and hospitalization the year preceding admission.

At the time of admission to the hospital, patients with anemia, uncontrolled diabetes, renal insufficiency, renal dilatation, and American Society of Anesthesiologists (ASA) score $\geq 2$ were significantly exposed to ESBL infections (Table 3).

The duration of hospitalization and the time spent in hospital before and after the surgery were noted to be predictors of ESBL infections ( $p=0.001$ and $p=0.009$, respectively). 
Table 2. Past history of patients presented with NAUTI caused by ESBL uropathogens

\begin{tabular}{lc}
\hline & $\begin{array}{c}\text { NAUTI caused by ESBL } \\
\mathbf{n = 2 7 6}(\%)\end{array}$ \\
\hline Underlying chronic disease & $139(50.4)$ \\
Hypertension & $63(22.8)$ \\
Diabetes & $61(22.1)$ \\
Heart diseases & $23(8.3)$ \\
UTI the last year & $12(43)$ \\
Past history of urinary lithiasis & $10(3.6)$ \\
The use of antibiotics the last year & $64(23.2)$ \\
TURP & $60(21.7)$ \\
Ureteroscopy & $55(19.9)$ \\
Transvesical adenomectomy & $33(12.0)$ \\
Urinary catheter & $276(100)$ \\
Transurethral catheter & $207(75.0)$ \\
Suprapubic catheter & $7(2.5)$ \\
Nephrostomy catheter & $81(29.3)$ \\
\hline ESBL: extended-spectrum beta-lactamase; NAUTI: nosocomially acquired urinary tract \\
infection; TURP: transurethral resection of the prostate; UTI: urinary tract infection.
\end{tabular}

There was a mean difference of three days stay in hospital between the two groups (Table 3).

The findings revealed that the use of three-way catheters, bladder washout, continuous bladder irrigation, and the duration of catheter use were highly associated with ESBL infections. A difference of more than three days during the catheter use was found between the two groups (Table 3 ).

Multivariate regression analysis performed with all significant variables found in the univariate analysis showed that only history of UTI in the past year, bladder washout, and the use of the catheterization for more than three days were found to be independent risk factors for ESBL infection in patients who underwent TURP (Table 4).

\section{Clinical presentation of NAUTI}

Asymptomatic bacteriuria was the most common type of NAUTI, accounting for $60.1 \%$ (166/276), followed by pyelonephritis at $27.9 \%(77 / 276)$. Urosepsis was found in $8.3 \%$ of patients (23/276) and cystitis in 2.2\% (6/276).

Table 3.Univariate regression analysis showing factors associated with significant risk of NAUTI caused by ESBL uropathogens in patients who underwent TURP

\begin{tabular}{|c|c|c|c|c|c|}
\hline & Case group $n=51(\%)$ & Control group $n=58(\%)$ & OR & $95 \% \mathrm{Cl}$ & $p$ value \\
\hline Past history of chronic disease & $25(49.0)$ & $28(48.3)$ & 1.03 & $0.09-2.19$ & 0.938 \\
\hline Hypertension & $16(31.4)$ & $11(19.0)$ & 1.95 & $0.81-4.75$ & 0.134 \\
\hline Diabetes & $13(25.5)$ & $11(19.0)$ & 1.46 & $0.59-3.63$ & 0.412 \\
\hline Heart disease & $5(9.8)$ & 6 (10.3.) & 0.94 & $0.27-3.29$ & 0.925 \\
\hline Renal insufficiency & $1(2.0)$ & $1(1.7)$ & 1.14 & $0.07-18.7$ & 0.927 \\
\hline Antibiotic thearpy the past year & $8(15.7)$ & $1(1.7)$ & 9.07 & $1.08-76.45$ & 0.024 \\
\hline Urological past history & $21(41.1)$ & $5(8.6)$ & 7.42 & $2.54-21.7$ & $<0.001$ \\
\hline UTI (previous year) & $7(13.7)$ & $1(1.7)$ & 9.07 & $1.08-76.45$ & 0.001 \\
\hline Urinary stones & $5(9.8)$ & $2(3.4)$ & 3.04 & $0.56-16.42$ & 0.249 \\
\hline Benign prostatic hyperplasia & $5(9.8)$ & $1(1.7)$ & 6.20 & $0.7-54.93$ & 0.096 \\
\hline Hospitalization (previous year) & $9(17.6)$ & $2(3.4)$ & 6.00 & $1.23-29.23$ & 0.022 \\
\hline \multicolumn{6}{|l|}{ Pathologies presented at the time of admission } \\
\hline Anemia & $11(21.6)$ & $3(5.2)$ & 5.04 & $1.32-19.25$ & 0.011 \\
\hline Uncontrolled diabetes & $10(19.6)$ & $3(5.2)$ & 4.47 & $1.16-17.29$ & 0.020 \\
\hline Renale insufficiency & $9(17.6)$ & $1(1.7)$ & 12.21 & $1.49-15.16$ & 0.005 \\
\hline Urinary distension & $12(23.5)$ & $4(6.9)$ & 4.15 & $1.25-13.85$ & 0.027 \\
\hline Urinary stones & $10(19.6)$ & $7(12.1)$ & 1.78 & $0.62-5.08$ & 0.27 \\
\hline Duration of the surgery (minutes) & $28 \pm 11.5$ & $26 \pm 10.4$ & 1.02 & $0.98-1.05$ & 0.332 \\
\hline Antibioprophylaxy & $47(92.2)$ & $50(86.2)$ & 1.88 & $0.53-6.66$ & 0.322 \\
\hline ASA score $\geq 2$ & $30(58.8)$ & $21(36.2)$ & 2.52 & $1.16-5.45$ & 0.021 \\
\hline Overall duration of the hospitalization (days) & $12 \pm 9$ & $6 \pm 2.3$ & 1.22 & $1.09-1.36$ & $<0.001$ \\
\hline Duration of hospitalization before surgery (days) & 6 days \pm 6 & 3 days \pm 2 & 1.26 & $1.08-1.47$ & 0.001 \\
\hline Duration of the hospitalization after surgery (days) & 5.7 days \pm 5.2 & 3.2 days \pm 1.5 & 1.26 & $1.06-1.5$ & 0.002 \\
\hline Three-way bladder catheter & $42(82.4)$ & $10(17.2)$ & 22.40 & $8.31-60.36$ & $<0.001$ \\
\hline Bladder irrigation & $29(56.9)$ & $10(17.2)$ & 6.33 & $2.36-15.24$ & $<0.001$ \\
\hline Bladder washout & $35(68.6)$ & $8(13.8)$ & 13.67 & $5.28-25.43$ & $<0.001$ \\
\hline Duration of the catheterization $>3$ days & $29(56.9)$ & $15(25.9)$ & 3.78 & $1.68-88.2$ & 0.001 \\
\hline
\end{tabular}




\begin{tabular}{|c|c|c|c|}
\hline & OR & $95 \% \mathrm{Cl}$ & $p$ value \\
\hline UTI (previous year) & 46.5 & $2.30-936.62$ & 0.012 \\
\hline Bladder washout & 40.4 & $8.90-183.52$ & $<0.001$ \\
\hline $\begin{array}{l}\text { Duration of the } \\
\text { catheterization }>3 \text { days }\end{array}$ & 44.5 & $2.60-848.23$ & 0.019 \\
\hline
\end{tabular}

\section{Treatment and evolution}

Probabilistic antibiotherapy was given to $30.8 \%$ (85/276) of patients. The most commonly used molecule was thirdgeneration cephalosporin. In fact, 68\% (188/276) of cases had received adapted antibiotherapy after antibiogram. Imipenem and amikacin were the most commonly used antibiotics (Table 5).

The mean duration of antibiotic therapy was 11 days (range: $2-45$ days). The outcome was favourable in $63.0 \%$ $(174 / 276)$ of the cases. However, infection relapsed and persisted in $27.2 \%$ (75/276 ) of cases, and 1.1\% (3/276) of patients died with urosepsis.

\section{Microorganisms and antibiotic resistance}

Overall, 10 microorganisms were identified in the isolates from the 276 patients with NAUTI caused by ESBL. The most common pathogen was Klebsiella pneumonia in 55.1\% $(152 / 276)$ of patients, followed by Escherichia coli in $24.3 \%$ (67/276). Both pathogens were responsible for ESBL infections in $80.0 \%(221 / 276)$ of patients (Fig. 1).

\section{Discussion}

The emergence of "newer" $\beta$-lactamases, such as ESBLs, was reported for the first time in $1983 .{ }^{10,11}$ Currently, there are geographic variations in the prevalence of ESBL infections. A study by Gossens et al $^{12}$ reported that during the years 1997-2000, the prevalence of ESBL infections was comparable between France and Germany (1-5\%) and higher in Italy (9-15\%), Great Britain (7-22\%), and Eastern Europe (Russia, Poland, and Turkey, 39-47\%)..$^{13}$ In our study the prevalence of ESBL infections was $1.9 \%$, with significant annual fluctuations (1.3\% in 2004 and $2.5 \%$ in 2007).

Although ESBL infections can occur at all ages, its predominance in older-age patients has often been observed. In fact, while several authors reported that age $>65$ years was predictor for ESBL infection, ${ }^{13,14}$ others have not confirmed this. ${ }^{15-17}$ In our study, $62 \%$ of patients were $>60$ years. Accordingly, age was not a risk factor, which could presumably be due to the selection bias.

\begin{tabular}{|c|c|}
\hline Antibiotics used & Cases, $\mathrm{n}=188(\%)$ \\
\hline Imipenem & $98(52.1)$ \\
\hline Amikacin & $70(37.2)$ \\
\hline Colymicin & $42(22.3)$ \\
\hline Trimethprime+sulfamethoxazole & $18(9.6)$ \\
\hline Nitrofurantoine & $18(9.6)$ \\
\hline Fluoroquinolone & $17(9.0)$ \\
\hline Gentamycin & $5(2.7)$ \\
\hline Fosfomycin & $2(1.1)$ \\
\hline
\end{tabular}

There is also controversy surrounding patient gender as a risk factor for ESBL infection. While Maki et $\mathrm{al}^{18}$ reported that ESBL infections is 3.7 more frequent in women and Lee et $\mathrm{al}^{19}$ also considered female gender a risk factor, other researchers have reported male gender as a predictor of ESBL infection. ${ }^{13,16}$ Still other authors reported there is no significant difference between males and females. ${ }^{15,20}$ Note that in our analytic study, all patients are male.

Several authors reported have that diabetes, chronic renal failure, hepatopathy, and cancer are risk factors for ESBL infections; ${ }^{13,21}$ others, however, have not stipulated chronic diseases as risk factors for ESBL UTIs. ${ }^{15,16}$ The results of the present study revealed that during hospitalization, uncontrolled diabetes, chronic renal failure, and anemia are associated with the emergence of ESBL UTIs after performing univariate analysis; however, after multivariate analysis, they do not represent independent risk factors for ESBL infection.

Our findings also indicated that a history of UTI in the year preceding hospital admission was an important risk factor in both the univariate $(\mathrm{p}<0.001)$ and multivariate analyses $(p=0.012)$, which is in agreement with several reports in literature. ${ }^{18,20-23}$ This can be explained by the previous use of antibiotics to treat these infections, which contributes to the selection of virulent pathogens. The overall cause of increasing antibiotic resistance is selective pressure by antimicrobial substances in various environmental settings. In most studies, the use of antibiotics in the preceding year is one of the strongest risk factors for developing ESBL infections. $13,14-16,18,19,23$ In our study, the use of antibiotic therapy in the year prior to hospital admission was a predictor of ESBL infection in the univariate analysis, but not an independent risk factor in the multivariate analysis.

One of the most important risk factor for NAUTI in urological patients is the contamination of the urinary tract due to indwelling catheters. ${ }^{1}$ The risk persists for at least 24 hours after catheterization because of the colonization of the urethra by pathogens..$^{24}$ In fact, several factors are involved, such as the duration of catheter use, the type of urinary catheter, the aseptic technique used for insertion, the 


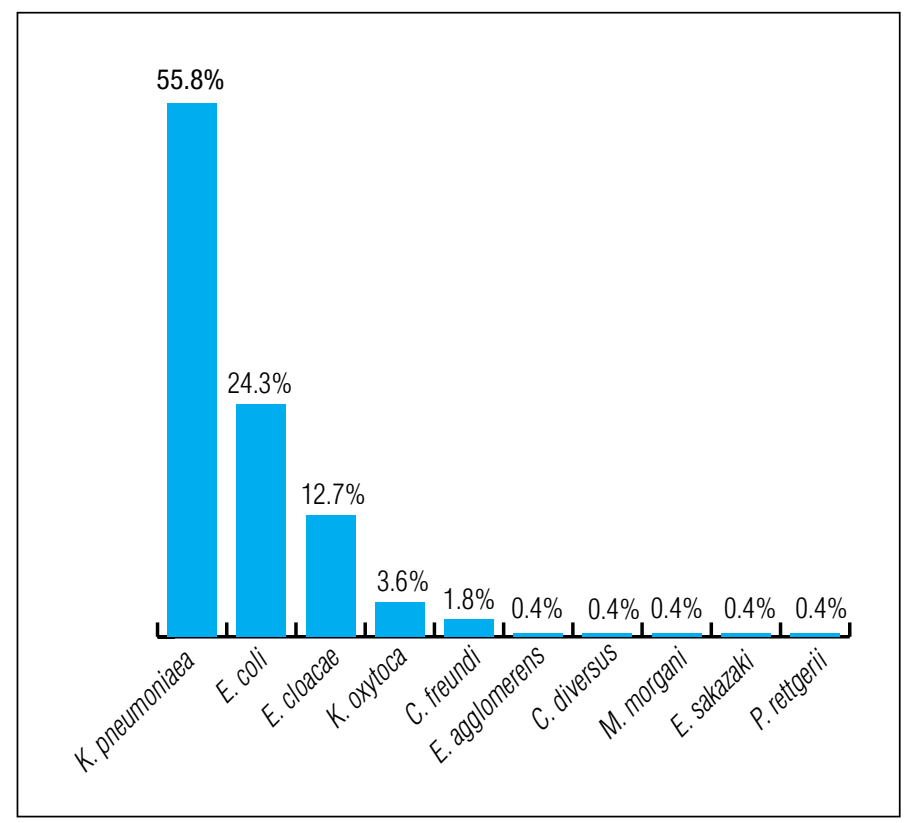

Fig. 1. Extended-spectrum beta-lactamase (ESBL) microbial species responsible for urinary tract infections.

manipulation of the system, and the expertise of the person who inserts the catheter.

\section{The duration of catheter use}

In a prospective study, Maki et al showed that risk factors are multiplied by 6.8 if the duration of catheter use exceeds six days. ${ }^{18}$ Johansen et al investigated data from PEP and PEAP studies and showed that long periods of catheter use resulted in a significant linear increase in the occurrence of Candida albicans. ${ }^{2}$ The results of our study revealed that a catheter duration exceeding three days was a risk factor for ESBL infections in both univariate $(p=0,001)$ and multivariate analysis $(p=0.019)$. This is probably due to the formation of bacterial biofilms developed around the catheters, which promote bacterial overgrowth.

\section{Types of catheter}

Several authors have reported that the incidence of bacteriuria was significantly reduced after the use of suprapubic catheter. However, this idea was not supported by the works of O'Kelly et al, Schiotz et al, and Bouza et al. ${ }^{24}$ Johansen et al even indicated an increased risk of a Proteus sp infection in patients with suprapubic catheter. ${ }^{2}$

\section{Insertion using an aseptic technique}

Catheters should be inserted by trained healthcare professionals using an aseptic technique, which can reduce the risk of UTIs from $14.3 \%$ to $12.3 \%{ }^{25}$ For Maki et al, ${ }^{18}$ the insertion of urinary catheter out of an operating room can multiply the risk of ESBL infections by 5.3. Garibaldi et $\mathrm{al}^{26}$ reported that urinary infection occurred in $34 \%$ of the cases when a catheter insertion was performed by novice nurses, a rate that dropped to $21 \%$ with experienced nurses, and to $10 \%$ with physicians.

\section{Closed drainage}

Once a catheter is inserted, the uncompromising maintenance of closed drainage becomes one of the highest priorities and can keep the overall risk of UTI $<25 \%$ for up to two weeks of catheterization. ${ }^{18,27}$

In our study, bladder washout represents a very high risk of ESBL infection in both univariate $(p<0.001)$ and multivariate analysis $(p<0.001)$. This can be explained by the manipulation of the system, the increase of the catheterization time, and the duration of hospitalization. All these factors favour the exposure of the patient to pathogen. We recommend urologists perform good hemostasis after endoscopic resections in order to avoid bladder irrigation and washout, and to allow a fast ablation of the catheter.

Some authors list duration of hospitalization is an independent risk factor of NAUTI. ${ }^{28}$ In a case-control study, Merle et al noted that the duration was one of the strongest risk factor of ESBL infections $(p<0.001) .{ }^{29}$ Likewise, Johansen et al reported that patients who had been hospitalized for any reason during the preceding six months present a significant risk for acquiring a Klebsiella sp or Pseudomonas sp as a causative pathogen. ${ }^{2}$ The results of our study revealed that the mean duration of hospitalization is highly correlated with NAUTI in the univariate analysis, but does not represent an independent risk factor for ESBL infection in the multivariate analysis.

Johansen et al found no significant association between the type of surgery and any bacterial species infection. ${ }^{2}$ Several authors have, however, reported that TURP represents a risk factor for NAUTI. ${ }^{30,31}$

The duration of surgery has long been implicated in nosocomial infections. This is not supported by our study, where duration of the surgery was not a risk factor $(p=0.332)$. This is supported by Girou et al. ${ }^{31}$

Urological departments should be encouraged to monitor the susceptibility of pathogens causing NAUTI in order to overcome the possibility of infection. Overall, the risk factors fall into three general categories: patient-related risk factors, device-related risk factors, and risk factors related to catheter insertion and care. ${ }^{25}$ Accordingly, several measures and policies need to be undertaken in hospitals to help control and prevent the risk of NAUTI.

Nurses and doctors in all hospital departments throughout the world are often involved in the insertion of urinary catheters. In a recent study, the European Study Group on 
Nosocomial Infections (ESGNI) of European Society for Clinical Microbiology and Infectious Diseases (ESCMID) showed that there was significant room for improvement in hospital guidelines on the indications for insertion and care for urinary catheters. ${ }^{5}$ It should be limited to patients requiring relief for anatomical or physiological outlet obstruction, patients undergoing surgical repair of the genitourinary tract, critically ill or postoperative patients who need their urinary output accurately measured, and comatose patients. Again, it is worth mentioning that the maintenance of closed drainage is of the highest priority and can keep the overall risk of $\mathrm{NAUTI}<25 \% .{ }^{29}$ The collection tubing or bags should also remain below the level of the patient's bladder.

The urologist must evaluate the surgery's contamination category, the patient-related risk factors, and the prophylactic administration of antibiotics. The elements of surgical skills are hard to define, but involve several factors pertaining to all the steps in the surgical procedure, including the way tissue and instruments are handled, the amount of bleeding, wound closure, and drainage.

Urologists have to perform a good hemostasis, especially in endoscopic resections in order to avoid bladder irrigation, bladder washout and to reduce the time of bladder catheterization, which is a strong risk factor of NAUTI infections. ${ }^{4}$

Nevertheless, our study has some limitations because it is a retrospective one and was performed on exclusively male patients of advanced age. Thus, the results cannot be generalized to the general population. Larger, prospective clinical studies with all age groups are required to minimize the selection bias.

\section{Conclusion}

The results revealed that the most important risk factors for ESBL infections included past history of UTI, bladder washout, and the duration of the catheterization. We recommend uologists perform good hemostasis after endoscopic resections in order to allow a fast ablation of the catheter.

Competing interests: The authors declare no competing financial or personal interests.

This paper has been peer-reviewed.

\section{References}

1. Johansen TE. Nosocomially acquired urinary tract infections in urology departments. Why an international prevalence study is needed in urology. Int J Antimicrob Agents 2004;23 Suppl 1:30-4. http://dx.doi. org/10.1016/i.jiantimicag.2003.09.003

2. Bjerklund Johansen TE, Cek M, et al. Prevalence of hospital-acquired urinary tract infections in urology departments. Eur Urol 2007;51:1100-11. http://dx.doi.org/10.1016/i.eururo.2006.08.012

3. Agodi A, Barch, Anzaldi A, et al. Active surveillance of nosocomial infections in urologic patients. Eur Urol 2007;51: 247-53. http://dx.doi.org/10.1016/i.eururo.2006.05.027
4. Johansen TE, Cek M, Naber KG, et al. Hospital acquired urinary tract infections in urology departments: Pathogens, susceptibility and use of antibiotics. Data from the PEP and PEAP-studies. Int I Antimicrob Agents 2006; 28 Suppl 1:91-107. http://dx.doi.org/10.1016/i.ijantimicag.2006.05.005

5. Rao AS, Baliga S, Ananthakrishma NC. Nosocomial urinary tract infections and mortality. Int J Gynaecol Obstet 1993;43: 201-02. http://dx.doi.org/10.1016/0020-7292(93)90334-S

6. Shukla I, Tiwari R, Agrawal M. Prevalence of extended spectrum -lactamase producing Klebsiella pnevmoniae in a tertiary care hospital. Indian J Med Microbiol 2004;22: 87-91.

7. Bradford PA: Extended-spectrum beta-lactamases in the 21 st century. Characterization, epidemiology, and detection of this important resistance threat. Clin Microbiol Rev 2001;14: 933-51. http://dx.doi. org/10.1128/CMR.14.4.933-951.2001

8. Chaudhary U, Aggarwal R. Extended spectrum -lactamases (ESBL) — an emerging threat to clinical therapeutics. Indian J Med Microbiol 2004;22:75-80.

9. Maina D, Revathi G, Kariuki S, et al. Genotypes and cephalosporin susceptibility in extended-spectrum beta-lactamase producing enterobacteriaceae in the community. I Infect Dev Ctries 2012;6:470-7. http:// dx.doi.org/10.3855/iidc. 1456

10. Trautner BW, Darouiche RO. Catheter-associated infections: pathogenesis affects prevention. Arch Intern Med 2004;164:842-50. http://dx.doi.org/10.1001/archinte.164.8.842

11. Pitout JD. Extraintestinal pathogenic Escherichia coli: A combination of virulence with antibiotic resistance. Front Microbiol 2012;3:9. http://dx.doi.org/10.3389/fmicb.2012.00009

12. Paterson DL, Bonomo RA. Extended-spectrum beta-lactamases: A clinical update. Clin Microbiol Rev 2005;18:657-86. http://dx.doi.org/10.1128/CMR.18.4.657-686.2005

13. Goossens, H. MYSTIC program: Summary of European data from 1997 to 2000. Diagn Microbiol Infect Dis 2001;41:183-9. http://dx.doi.org/10.1016/S0732-8893(01)00320-0

14. Ben-Ami R, Schwaber MJ, Navon-Venezia $S$, et al. Influx of extended-spectrum beta-lactamaseproducing enterobacteriaceae into the hospital. Clin Infect Dis 2006;42:925-34. http://dx.doi. org/10.1086/500936

15. Ena J, Ariona F, Martínez-Peinado C. Epidemiology of urinary tract infections caused by extended-spectrum beta-lactamase-producing Escherichia coli. Urology 2006;68:1169-74. http://dx.doi.org/10.1016/i. urology.2006.08.1075

16. Kuster SP, Hasse B, Huebner V,et al. Risks factors for infections with extended-spectrum beta-lactamaseproducing Escherichia coli and Klebsiella pneumoniae at a tertiary care university hospital in Switzerland. Infection 2010;38:33-40. http://dx.doi.org/10.1007/s15010-009-9207-z

17. Yang YS, Ku CH, Lin JC, et al. Impact of extended-spectrum beta-lactamase-producing Escherichia coli and Klebsiella pneumoniae on the outcome of community-onset bacteremic urinary tract infections. J Microbiol Immunol Infect 2010;43:194-9. http://dx.doi.org/10.1016/S1684-1182(10)60031-X

18. Maki DG, Tambyah PA. Engineering out the risk for infection with urinary catheters. Emerg Infect Dis 2001;7:342-7. http://dx.doi.org/10.3201/eid0702.010240

19. Lee DS, Lee CB, Lee SJ. Prevalence and risk factors for extended spectrum Beta-lactamase-producing uropathogens in patients with urinary tract infection. Korean J Urol 2010;51:492-7. http://dx.doi. org/10.4111/kju.2010.51.7.492

20. Azap OK, Arslan H, Serefhano lu K, et al. Risk factors for extended-spectrum beta-lactamase positivity in uropathogenic Escherichia coli isolated from community-acquired urinary tract infections. Clin Microbiol Infect 2010;16:147-51. http://dx.doi.org/10.1111/i.1469-0691.2009.02941.x

21. Rodríguez-Ba-0 J, Alcalá JC, Cisneros JM, et al. Community infections caused by extended-spectrum beta-lactamase-producing Escherichia coli. Arch Intern Med 2008;168:1897-902. http://dx.doi. org/10.1001/archinte.168.17.1897

22. Rodríguez-Ba-0 J, López-Prieto MD, Portillo MM, et al. Epidemiology and clinical features of communityacquired, healthcare-associated and nosocomial bloodstream infections in tertiary-care and community hospitals. Clin Microbiol Infect2010;16:1408-13.http://dx.doi.org/10.1111/j.1469-0691.2010.03089.x

23. Ortega M, Marco F, Soriano A, et al. Analysis of 4758 Escherichia coli bacteremia episodes: Predictive factors for isolation of an antibiotic-resistant strain and their impact on the outcome. J Antimicrob Chemother 2009;63:568-74. http://dx.doi.org/10.1093/jac/dkn514

24. Calbo $E$, Romani $V$, Xercavins $M$, et al. Risk factors for community-onset urinary tract infections due to Escherichia coli harbouring extended-spectrum beta-lactamases. J Antimicrob Chemother 2006;57:780-3. http://dx.doi.org/10.1093/jac/dkl035

25. Hartstein Al, Garber SB, Ward TT, et al. Nosocomial urinary tract infection: A prospective evaluation of 108 catheterized patients. Infect Control 1981;2:380-6.

26. Garibaldi RA, Burke JP, Dickman ML, et al. Factors predisposing to bacteriuria during indwelling urethral catheterization. N Engl J Med 1974;291:215-9. http://dx.doi.org/10.1056/ NEJM197408012910501

27. O'Kelly TJ, Mathew A, Ross S, et al. Optimum method for urinary drainage in major abdominal surgery: A prospective randomized trial of suprapubic versus urethral catheterization. Br I Surg 1995;82:1367-8. http://dx.doi.org/10.1002/bjs.1800821024 
UTIs caused by ESBL

28. Wagenlehner $F M$, Loibl $E$, Vogel $H$, et al. Incidence of nosocomial urinary tract infections on a surgical intensive care unit and implications for management. Int J Antimicrob Agents 2006;28:86-90. http:// dx.doi.org/10.1016/i.ijantimicag.2006.05.011

29. Merle V, Germain JM, Bugel $H$, et al. Nosocomial urinary tract infections in urologic patients: Assessment of a prospective surveillance program including 10000 patients. Eur Urol 2002;41:483-9. http://dx.doi. org/10.1016/S0302-2838(02)00069-6

30. Colau A. Infections nosocomiales après résection trans-uréthrale de la prostate. Prog Urol 1999;9:57-60.
31. Girou E, Rioux C, Brun-Buisson C, et al. The prospective bacteriuria score: A new way to predict nosocomial infection after prostate surgery. Infect Control Hosp Epidemiol 2006;27:847-54. http://dx.doi. org/10.1086/506398

Correspondence: Dr. Khaireddine Bouassida, Department of Urology, Hospital of Sahloul, Sousse, Tunisia; khayril4@hotmail.com 